\title{
Acute Myelomonocytic Leukemia
}

National Cancer Institute

\section{Source}

National Cancer Institute. Acute Myelomonocytic Leukemia. NCI Thesaurus. Code

C7463.

An acute leukemia characterized by the proliferation of both neutrophil and monocyte precursors. (WHO, 2001) 